\title{
FLUTUAÇÃO POPULACIONAL DO PERCEVEJO-PRETO-EM AMENDOIM ATRAVÉS DE ARMADILHAS DE QUEDA
}

Ítalo Antonieto de Lima Lima ${ }^{1}$; Maycon Ferraz; Rogério Soares de Freitas ${ }^{3}$; Denizart Bolonhezi ${ }^{4}$; Ignácio José Godoy ${ }^{5}$; Marcos Doniseti Michelotto ${ }^{6}$

1'Graduando em Agronomia, Unirp, italoantonieto@hotmail.com; ${ }^{2}$ Graduando em Agronomia, Unirp; ${ }^{3}$ Doutor em Agronomia; ${ }^{4}$ Doutor em Agronomia; ${ }^{5}$ Doutor em Agronomia; ${ }^{6}$ Doutor em Agronomia

RESUMO: O presente trabalho teve como objetivo monitorar a flutuação populacional do percevejopreto, Cyrtomenus mirabilis (Perty), em áreas de amendoim, através de armadilhas de queda. Foram instaladas 10 armadilhas de queda em três locais: Pindorama, Ribeirão Preto e Votuporanga, SP, avaliadas antes e após a semeadura do amendoim. Os insetos capturados foram contabilizados a cada dez dias. Foram capturados tanto ninfas de últimos estádios quanto adultos do percevejo-preto. Os resultados permitem concluir que as armadilhas de queda são eficientes para coleta tanto de ninfas de últimos estádios, quanto de adultos de C. mirabilis; Há maiores picos de coleta antes da semeadura do amendoim e; A partir dos 60-70 dias após a semeadura do amendoim as armadilhas de queda não capturam mais ninfas ou adultos do percevejo.

Palavras-chave: Arachis hypogaea; praga-de-solo, monitoramento.

\section{INTRODUÇÃO}

Os percevejos-cavadores (Hemiptera: Cydnidae), como são conhecidos, são fitófagos e a maioria das espécies provavelmente polífagas (FROESCHNER, 1960, LIS et al., 2000). O grupo tem sido considerado de pouca importância econômica (LIS et al. 2000), no entanto os danos às culturas na região Neotropical têm crescido nos últimos 15 anos (OLIVEIRA et al. 2000).

As espécies de importância econômica na região Neotropical são incluídas nos gêneros Cyrtomenus e Pangaeus Stål, na qual ninfas e adultos alimentam-se de raízes, tubérculos (RIIS et al. 2005) e frutos de solo (RIIS et al. 2005, CHAPIN et al. 2004, 2006), reduzindo a produtividade em amendoim e facilitando infecções pelos patógenos de solo, por exemplo, os fungos Fusarium, Aspergillus e Pythium (RIIS et al. 2005), além do desenvolvimento de aflatoxinas (CHAPIN et al. 2004).

O percevejo-preto, Cyrtomenus mirabilis (Perty, 1830), possui distribuição em praticamente toda a América continental, desde os Estados Unidos até o Uruguai e Argentina. C. mirabilisé é considerada uma espécie importante nas culturas de amendoim no Peru, Paraguai, Argentina e Brasil (FROESCHNER 1960, ZUCCHI et al. 1993, GALLO et al. 2002). 
Em amendoim, seus danos estão relacionados ao ataque em vagens na fase de desenvolvimento dos grãos, na qual ninfas e adultos inserem o estilete de seu aparelho bucal, atingindo os grãos em desenvolvimento. Ao se alimentarem dos grãos, os mesmos tornam-se manchados impróprios para comercialização (CHAPIN; THOMAS, 2003).

Como é um inseto que passa grande parte de sua vida no solo, há grande dificuldade de se constatar sua presença na área. Muitas vezes sua constatação se dá somente quando o amendoim colhido é beneficiado e assim medidas de controle já não são mais possíveis. CHAPIN \& THOMAS (2003) verificaram que o uso de armadilhas de queda foram eficientes para realizar o monitoramento de adultos e ninfas de quarto e quinto estádios de Pangeaus bilineatus (Say) em amendoim.

Dessa forma, o objetivo deste trabalho foi avaliar a flutuação populacional do percevejo-preto através de armadilhas de queda em pré e pós-semeadura do amendoim em três localidades do Estado de São Paulo.

\section{MATERIAIS E MÉTODOS}

Foram instaladas 10 armadilhas de queda em cada uma das três localidades do Estado de São Paulo, Pindorama (Polo Centro Norte/Apta), Ribeirão Preto (Centro de Cana/IAC) e Votuporanga (Centro de Seringueira/IAC). Estes locais foram escolhidos por terem apresentado histórico de ocorrência de grãos com danos do percevejo na safra 2016/17.

As armadilhas foram instaladas nos dias 05, 15 e 25 de setembro de 2017 em Pindorama, Ribeirão Preto e Votuporanga, respectivamente. As datas de semeadura foram 30 de outubro, 01 de novembro e 01 de dezembro de 2017 em Pindorama, Ribeirão Preto e Votuporanga, respectivamente. $\mathrm{Na}$ semana de semeadura as armadilhas foram retiradas, e após a semeadura, recolocadas, permanecendo nos locais até a colheita do amendoim na área. As cultivares de amendoim semeadas nas áreas foram IAC OL3 e IAC 503 na densidade de 20 sementes por metro, nos três locais.

Estas armadilhas de queda consistem de copos plásticos de $500 \mathrm{ml}$, enterrados de forma que estes fiquem ao nível do solo. Para aumentar a superfície de coleta, foi instalada lateralmente à abertura do copo uma chapa de ferro de $50 \mathrm{~cm}$ de comprimento e $10 \mathrm{~cm}$ de altura. Além disso, para evitar que os copos ficassem cheios com águas de chuva, as mesmas foram cobertas com estrutura de metal.

As mesmas foram inspecionadas semanalmente para a contagem de ninfas e adultos dos percevejos. Posteriormente foram elaborados os gráficos de ocorrência dos mesmos ao longo do período que antecede a semeadura e posterior a semeadura do amendoim.

\section{RESULTADOS E DISCUSSÃO}

Nas armadilhas instaladas em Pindorama, coletou-se tanto adultos quanto ninfas atingindo um pico no dia 15 de setembro de 2017 com 12,4 adultos/armadilha em 10 dias (Figura 1). Na mesma data 
ocorreu o pico de coleta de ninfas com 3,6 ninfas/armadilha. Posteriormente, houve uma queda até a data de semeadura. Importante ressaltar que as ninfas coletadas nas armadilhas de queda são aquelas nos últimos estádios ninfais próximas a se tornarem adultas. Posteriormente à semeadura, houve um novo pico de adultos aos 16 DAS (Dias Após Semeadura) (15 de novembro) com 2,8 percevejos/armadilha e posterior queda coletando-se sempre abaixo de 1 adulto/armadilha até os 67 DAS (05 de janeiro de 2018). À partir desta data não houve mais captura de adultos ou ninfas nas armadilhas em Pindorama (Figura 1).

Em Votuporanga, logo após a instalação das armadilhas, houve um pico de captura tanto de adultos, no dia 25 de setembro de 2017 (10,8 adultos/armadilha), quanto de ninfas, no dia 15 de setembro de 2017 (3,6 ninfas/armadilha), conforme Figura 2. Posteriormente, houve queda no número de ninfas e adultos até o momento da semeadura, quando houve interrupção da coleta. Após a semeadura, no dia 01 de dezembro de 2017, houveram pequenas capturas tanto de adulto, quanto de ninfas, chegando a 0,8 adultos/armadilha, no dia 25 de dezembro de 2017 (24 DAS). As armadilhas de queda capturaram percevejos até o dia 05 de fevereiro de 2018, ou seja, até os 66 DAS. À partir desta data não houve mais captura de percevejos pelas armadilhas em Votuporanga (Figura 2).

Em Ribeirão Preto, as armadilhas de queda não capturaram muitos percevejos antes da semeadura diferentemente do que ocorreu em Pindorama e Votuporanga. O pico de captura de adultos se deu entre 05 e 15 de dezembro de 2017 com 1,3 e 1,4 adultos/armadilha, respectivamente. Já as ninfas foram capturadas em número muito baixo se comparado aos outros locais avaliados. Mas observou o mesmo comportamento observado nos outros locais em que as armadilhas capturam percevejos até os 60 DAS (Figura 3). Ao observar a captura do percevejo-preto nas armadilhas de queda nas três localidades, fica evidente que tanto ninfas quanto adultos caminham na superfície do solo provavelmente à procura de alimento e acabam caindo nas armadilhas. Na contagem antes da semeadura, obteve-se cerca de 35,5 adultos/armadilha em Pindorama/SP; 29,1 percevejos/armadilha em Votuporanga/SP, e 1,6 percevejos/armadilha em Ribeirão Preto/SP.

Após o preparo do solo e a semeadura, ocorreu uma diminuição na captura até aos 60-70 DAS, quando as plantas de amendoim começam a ter as primeiras vagens com grãos, não sendo necessário o inseto sair do solo à procura de alimento. 
16 e 17 de agosto de 2018, centro de convenções da FCAV/UNESP - Câmpus de Jaboticabal, SP

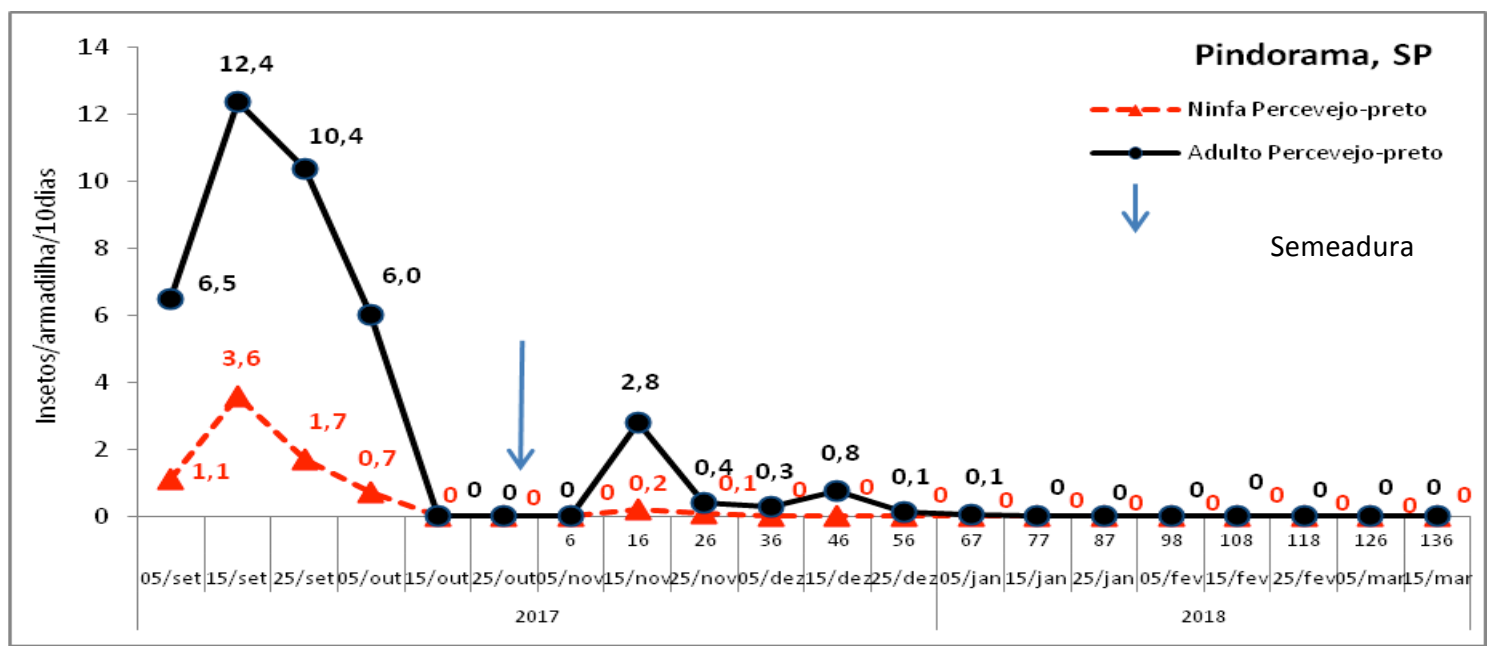

Figura 1. Ninfas e adultos de Cyrtomenus mirabilis capturados em armadilhas de queda em pré e póssemeadura de amendoim em Pindorama, SP. Safra 2017/18.

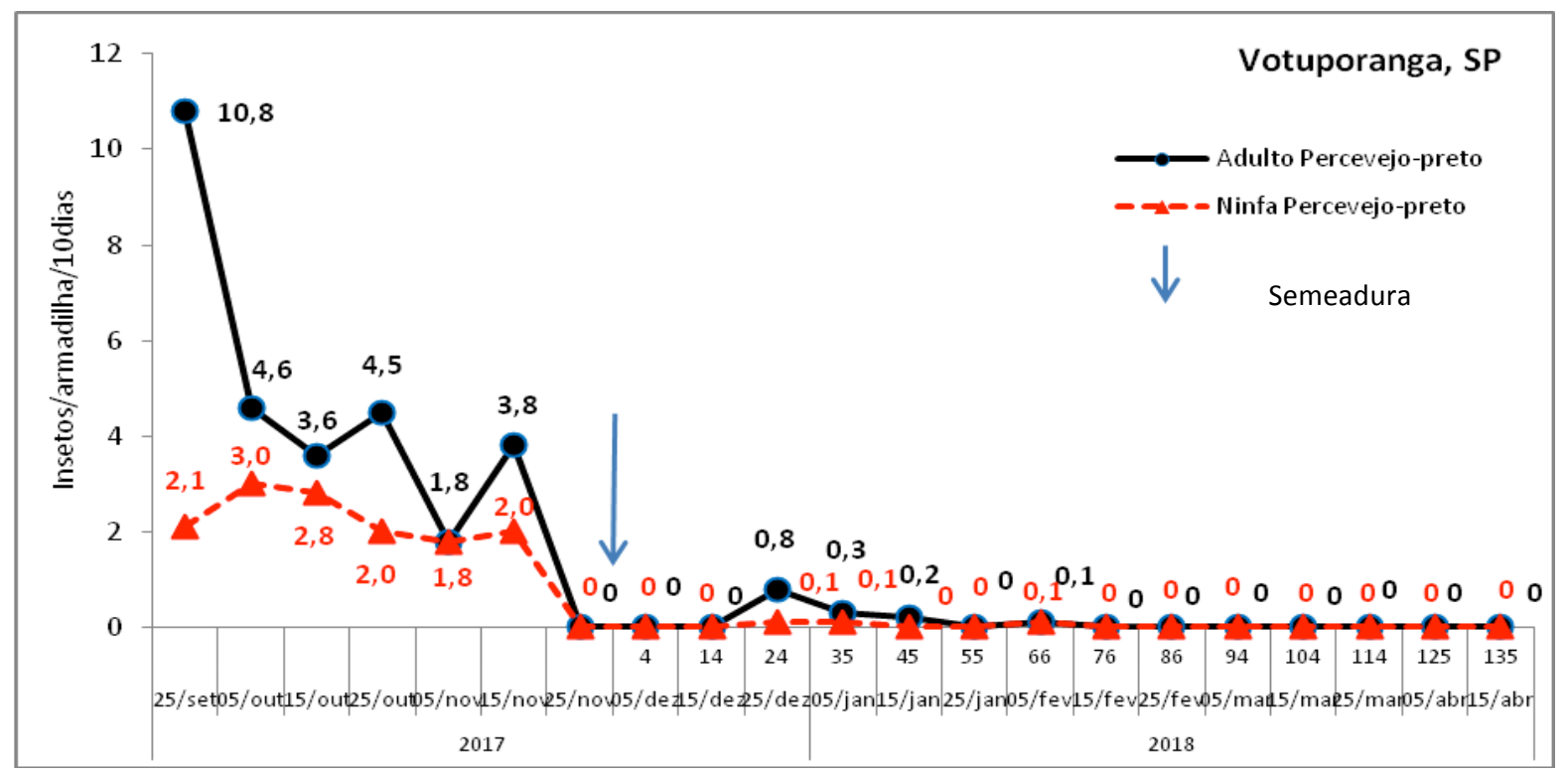

Figura 2. Ninfas e adultos de Cyrtomenus mirabilis capturados em armadilhas de queda em pré e póssemeadura de amendoim em Votuporanga, SP. Safra 2017/18. 
16 e 17 de agosto de 2018, centro de convenções da FCAV/UNESP - Câmpus de Jaboticabal, SP



Figura 3. Ninfas e adultos de Cyrtomenus mirabilis capturados em armadilhas de queda em pré e póssemeadura de amendoim em Ribeirão Preto, SP. Safra 2017/18.

\section{CONCLUSÃO}

As armadilhas de queda são eficientes para coleta tanto de ninfas de últimos estádios, quanto de adultos de C. mirabilis.

Há maiores picos de coleta antes da semeadura do amendoim.

A partir dos 60-70 dias após a semeadura do amendoim as armadilhas de queda não capturam mais ninfas ou adultos do percevejo.

\section{REFERENCIAS BIBLIOGRÁFICAS}

CHAPIN, J.W.; DORNER J.W.; THOMAS, J.S. Association of a burrower bug (Heteroptera: Cydnidae) with aflatoxin contamination of peanut kernels. Journal of Entomological Science, v.39, p.71-83, 2004.

CHAPIN, J.W.; SANDERS, T.H.; DEAN, L.O. Effect of feeding by a burrower bug, Pangaeus bilineatus (Say) (Heteroptera: Cydnidae), on peanut flavor and oil quality. Journal of Entomological Science, v.41, p.33-39, 2006.

FROESCHNER, R.C. Cydnidae of the Western Hemisphere. Proceedings of the United States National Museum, v.111, p.337-680, 1960.

GALLO, D.; NAKANO, O.; SILVEIRA NETO, S.; CARVALHO, R.P.L.; BAPTISTA, G.C.; BERTI FILHO, E.; PARRA, J.R.P.; ZUCCHI, R.A.; ALVES, S.B.; VENDRAMIM, J.D.; MARCHINI, L.C., LOPES, J.R.S.; OMOTO, C. Entomologia Agrícola. Fealq, Piracicaba, SP, Brasil.2002. 
LIS, J.A.; BECKER, M.; SCHAEFER, C.W. Burrower bugs (Cydnidae). In: SCHAEFER, C.W., PANIZZI, A.R. (Eds) Heteroptera of economic importance, CRC Press, London, New York, Washington, p 405-419,2000.

OLIVEIRA, L.J.; MALAGUIDO, A.B.; NUNES JR, J.; CORSO, I.C.; DEANGELIS, S.; FARIAS, L.C.; HOFFMANN-CAMPO, C.B.; LANTMANN, A. Percevejos castanhos da raiz em sistemas de produção de soja. Embrapa-Soja, Londrina, PR, Brasil. 2000. 